\title{
Atuação do enfermeiro no cuidado à criança frente à COVID-19: revisão integrativa
}

\author{
Nurse's role in child care in the face of COVID-19: integrative review
}

El papel de la enfermera en el cuidado infantil frente al COVID-19: revisión integradora

Alex Sandra Avila Minasi ${ }^{1 *}$, Giovana Calcagno Gomes ${ }^{1}$, Pâmela Kath de Oliveira Nörnberg ${ }^{1}$, Stella Minasi de Oliveira ${ }^{1}$, Camila Magroski Goulart Nobre ${ }^{1}$.

\section{RESUMO}

Objetivo: Revisar a produção científica acerca da atuação do enfermeiro no cuidado à criança frente à Covid19. Métodos: Revisão integrativa realizada no primeiro trimestre de 2021 nas bases de dados Scientific Electronic Library Online, Literatura Latino - Americana e do Caribe em Ciências da Saúde, Base de Dados de Enfermagem; Medical Literature Analysis and Retrieval System Online e na Public Medline. Incluíram-se artigos publicados integralmente em português, inglês ou espanhol, ter resumos e textos completos disponíveis online para análise, entre os anos de 2019 a 2021, e apresentar nos resultados aspectos acerca da atuacão do enfermeiro no cuidado à criança frente à Covid-19 submetidos à síntese qualitativa. Resultados: Captaram-se 11 artigos. Verificou-se que o enfermeiro realiza pesquisas na área para buscar conhecimentos e manter-se atualizado acerca da temática; cuida de crianças com comorbidades; prepara e realiza exames diagnósticos da COVID-19; atua como membro da equipe multiprofissional de saúde e durante a internação hospitalar da criança. Considerações Finais: A atuação do enfermeiro é multifacetada no cuidado à criança frente a pandemia da COVID-19.

Palavras-chave: Coronavírus, Criança, Enfermagem.

\begin{abstract}
Objective: Review the scientific production about the role of nurses in child care in front of Covid-19. Methods: Integrative review carried out in the first quarter of 2021 in the Scientific Electronic Library Online, Latin American and Caribbean Literature in Health Sciences, Nursing Database; Medical Literature Analysis and Retrieval System Online and Public Medline. Articles fully published in Portuguese, English or Spanish were included, with abstracts and full texts available online for analysis, between the years 2019 to 2021, and presenting in the results aspects about the role of nurses in child care in front of Covid-19 submitted to qualitative synthesis. Results: 11 articles were captured. It was found that nurses carry out research in the area to seek knowledge and keep up-to-date on the subject; takes care of children with comorbidities; prepares and performs COVID-19 diagnostic tests; acts as a member of the multidisciplinary health team and during the child's hospital stay. Final Considerations: The role of nurses is multifaceted in child care in the face of the COVID-19 pandemic.
\end{abstract}

Keywords: Coronavirus, Child, Nursing.

\section{RESUMEN}

Objetivo: Revisión la producción científica sobre el rol del enfermero en el cuidado infantil frente al Covid-19. Métodos: Revisión integradora realizada en el primer trimestre de 2021 en la Biblioteca Científica Electrónica en Línea, Literatura Latinoamericana y del Caribe en Ciencias de la Salud, Base de Datos de Enfermería; Sistema de Análisis y Recuperación de Literatura Médica Online y Public Medline. Se incluyeron artículos íntegramente publicados en portugués, inglés o español, con resúmenes y textos completos disponibles en línea para su análisis, entre los años 2019 a 2021, y presentando en los resultados aspectos sobre el papel de las enfermeras en el cuidado infantil en relación al Covid-19 presentado. a la síntesis cualitativa. Resultados: Se capturaron 11 artículos. Se encontró que los enfermeros realizan investigaciones en el área para buscar conocimientos y mantenerse actualizados sobre el tema; atiende a niños con comorbilidades; prepara y realiza pruebas de diagnóstico de COVID-19; actúa como miembro del equipo multidisciplinario de salud y durante la estancia hospitalaria del niño. Consideraciones finales: El papel de las enfermeras es multifacético en el cuidado infantil frente a la pandemia de COVID-19.

Palabras clave: Coronavirus, Niño, Enfermería.

1 Universidade Federal do Rio Grande (FURG), Rio Grande - RS. *E-mail: alexsandra@furg.br 


\section{INTRODUÇÃO}

No final do ano de 2019, surgiu uma epidemia caracterizada pelo aumento de pacientes com infecção respiratória originário de um novo coronavírus (CoV), já que os dados de sequenciamento genômico inicial deste vírus não correspondiam aos CoVs sequenciados anteriormente. Esta nova cepa de CoV foi identificada pela sigla COVID-19 (2019-nCoV), denominado atualmente como Síndrome Respiratória Aguda Grave COV2 (SARS-Cov-2). Seu surgimento ocorreu no Mercado Central, mercado de frutos do mar, na Cidade de Wuhan, província de Hubei, na China e se espalhou rapidamente por todo o país e, posteriormente, para outras regiões (TRILLA A, 2020; WORLD HEALTH ORGANIZATION (WHO), 2020).

Essa epidemia se disseminou rapidamente tomando proporções mundiais. Devido à gravidade deste surto e o potencial de propagação em escala internacional, em 31 de janeiro de 2020 a Organização Mundial de Saúde (OMS) considerou esta doença como sendo uma Emergência de Saúde Pública de Interesse Internacional e, posteriormente, em 11 de março de 2020 passou a considerá-la como Pandemia (TRILLA A, 2020; WHO, 2020).

O COVID-19 é uma doença infecciosa causada pelo vírus SARS-CoV-2. A forma de manifestação desta infecção pode ser assintomática, leve ou moderada, grave ou crítica. Dentre os sintomas, os pacientes podem apresentar, nos casos leves de COVID-19, tosse, dor de garganta, temperatura alta, diarreia, dor de cabeça, dores musculares ou articulares, fadiga e hiposmia/anosmia (diminuição/perda do olfato) e hipogeusia/ageusia (diminuição/perda paladar). Em casos graves, como pneumonias por COVID-19, os sintomas podem incluir falta de ar, perda de apetite, confusão, dor ou pressão no peito e temperatura elevada (acima de $38^{\circ} \mathrm{C}$ ), em alguns episódios requer suporte de oxigênio. Nos casos considerados críticos devido à síndrome respiratória aguda grave (SARS) os pacientes necessitam de cuidados intensivos, pelo risco de choque ou disfunção de outro órgão (STRUYF T, et al., 2020).

De acordo com as evidências atuais, em relação à patogenicidade do SARS-CoV-2, a principal forma do vírus se espalhar é através dos núcleos das gotículas ou pequenas partículas transmitidas pelo ar. Estás, ainda, precisarão entrar em contato com mucosas da boca, nariz, olhos, ou outras partes do sistema aero digestivo superior do paciente ou por transmissão feco-oral (GU J, et al., 2020). Em relação a transmissão transplacentária da infecção por SARS-CoV-2, estudo aponta que é possível a ocorrência durante as últimas semanas de gravidez, podendo causar inflamação placentária e viremia neonatal (VIVANTI AJ, et al., 2020).

No tocante a prevenção da transmissão a COVID-19, algumas práticas de precaução são recomendáveis. Elas incluem a higiene das mãos, o uso de Equipamento de Proteção Individual (EPI) e etiquetas respiratórias e de tosse. Como etiquetas respiratórias a serem seguidas são: cobrir o nariz e a boca ao espirrar e tossir, usar lenço de papel descartável, em vez de pano de algodão. EPI como máscaras faciais, e para profissionais de saúde, protetores faciais ou óculos de proteção, batas, luvas e protetores de calçados (ORGANIZAÇÃO PAN-AMERICANA DE SAÚDE (OPAS), 2020).

Embora a COVID-19 tenha sido relatada em todas as faixas etárias, apenas cerca de $2 \%$ dos casos confirmados são de crianças (WU C, et al., 2020). Esse vírus é considerado altamente contagioso, e embora o número de crianças notificadas seja menos expressivo em comparação com o restante da população, elas também são vulneráveis à infecção (VILELAS JMS, 2020).

As crianças parecem ter menos probabilidade de desenvolver a forma grave de infecção pelo SARS-CoV2. Apresentam-se, normalmente, com sintomas clinicamente leves e demoram pouco tempo para se restabelecerem. Apresentam um prognóstico melhor em comparação com os adultos, e a morte é um evento esporádico. Crianças com doenças subjacentes, podem, ainda, representar categorias com maior risco e exigir maior atenção e cuidados (LASSANDRO G, et al., 2020). Muitas razões são aventadas em relação ao fato das crianças não representarem população de risco, dentre elas sistema imunológico ainda imaturo, trato respiratório mais saudável e presença de menos doenças subjacentes (LEE B e RASZKA W, 2020).

Diante das incertezas oriundas da pandemia pela COVID-19 a enfermagem possui um lugar importante para contribuir nas respostas clínicas e científicas. Possui competência para atender holisticamente as necessidades humanas em evolução por meio de teoria, pesquisa e inovação. Além, de ser uma profissão que adapta e traduz a ciência em prol da prática, ao mesmo tempo, responde às necessidades humanas e atua em diversas áreas, possuindo capacidade para informar e apoiar a prevenção, o tratamento e o cuidado das pessoas afetadas direta ou indiretamente pela COVID-19 (WIERENGA KL e MOORE SE, 2020). 
É importante ter subsídios científicos que possibilitem a compreensão do contexto mundial em torno da COVID-19, assim como da atuação da enfermagem na prevenção da doença e no tratamento das crianças infectadas. Do mesmo modo, intervenção e atuação assertiva da enfermagem nos cuidados à criança e sua família. Diante do exposto, o presente estudo objetivou conhecer a produção científica acerca da atuação do enfermeiro no cuidado à criança frente à Covid-19.

\section{MÉTODOS}

Trata-se de uma revisão integrativa realizada por meio da investigação e síntese de estudos disponíveis sobre determinada temática, seguindo as seguintes etapas: 1) elaboração da questão de pesquisa;2) busca na literatura; 3) avaliação dos dados - foco na qualidade; 4) análise dos dados - divisão, exposição e comparação; 5) apresentação dos resultados (WHITTEMORE R e KNAFI K, 2005). A questão de pesquisa foi construída embasada na estratégia PICo (P- população: enfermeiros; I- Interesse: atuação no cuidado à criança; Co- Contexto: da Covid-19), o que resultou na seguinte questão norteadora: Qual a produção científica acerca da atuação do enfermeiro no cuidado à criança frente à Covid-19?

A busca nas bases de dados ocorreu no primeiro trimestre de 2021, nas bases de dados Scientific Electronic Library Online (SCIELO), Literatura Latino - Americana e do Caribe em Ciências da Saúde (LILACS), Base de Dados de Enfermagem (BDENF), na Medical Literature Analysis and Retrieval System Online (MEDLINE) e na Public Medline (PubMed) de revistas especializadas acerca do tema, publicados entre os anos de 2019 à 2021. Utilizou-se os descritores coronavírus, criança, enfermagem com o operador boleano "and" entre eles.

Os critérios de inclusão foram: ser artigo científico, estar no idioma português, inglês ou espanhol; ter resumos e textos completos disponíveis online para análise e apresentar nos resultados aspectos acerca da atuação do enfermeiro no cuidado à criança frente à Covid-19. Foram excluídas publicações classificadas como editorial, cartas, dissertações e teses. A busca dos artigos foi realizada de forma independente por duas pesquisadoras. Os resultados das duas pesquisadoras foram comparados e as diferenças solucionadas por consenso. Os resultados e conclusões dos estudos captados foram analisados pela técnica de análise temática (MINAYO MCS, 2014). Ainda, foram considerados a classificação do nível de evidência preconizado pelo Oxford Centre for Evidence-Based Medicine (OCFEM) (2009).

A busca capturou 323 produções científicas nas bases analisadas e, após aplicação dos critérios de inclusão, elegibilidade e exclusão restaram 11 artigos que compuseram a amostra do presente estudo, todos publicados no ano de 2020, foram obtidos na íntegra para categorização, avaliação e síntese, conforme apresentado no Fluxograma de Seleção da Figura 1.

Figura 1 - Fluxograma de seleção dos artigos.

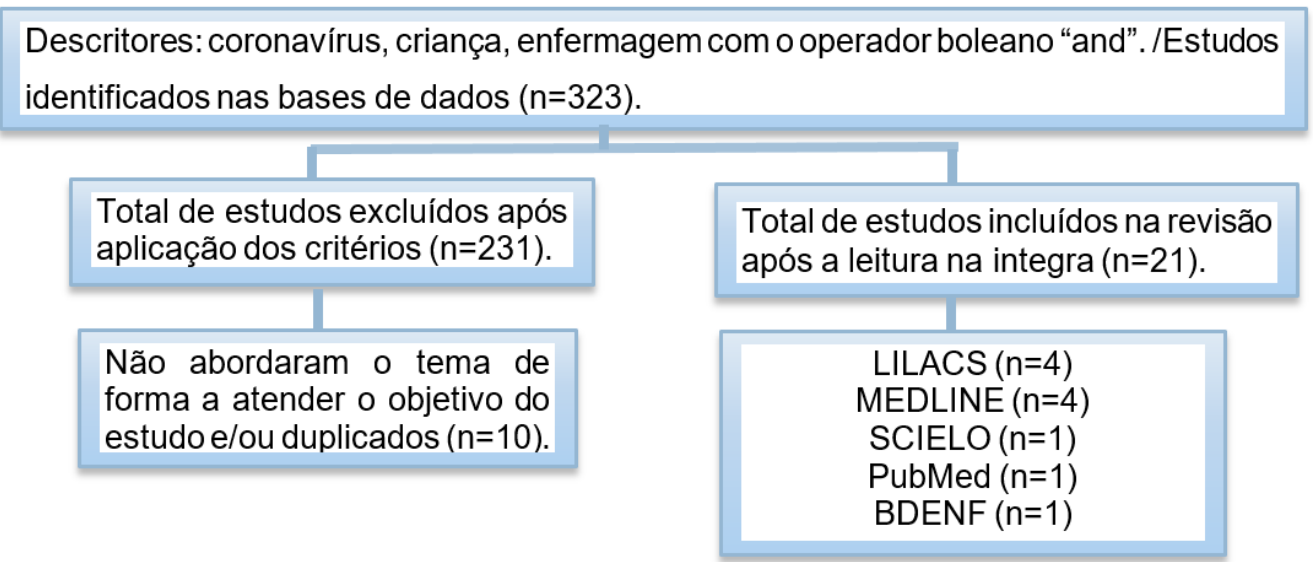

Fonte: Minasi ASA, et al., 2021.

\section{RESULTADOS}

O Quadro 1 descreve os 11 artigos selecionados que compuseram a presente revisão. Na apresentação, os artigos selecionados foram listados de acordo com a base de dados, título, tipo de pesquisa e nível de evidência, autores, local de estudo, periódico publicado/país e sujeitos envolvidos. 
Quadro 1 - Síntese dos artigos selecionados.

\begin{tabular}{|c|c|c|c|c|c|c|c|}
\hline № & Base de dados & $\begin{array}{r}\text { Título } \\
\end{array}$ & $\begin{array}{c}\text { Tipo de pesquisa e nível } \\
\text { de evidência }\end{array}$ & Autores & Local de estudo & $\begin{array}{c}\text { Periódico } \\
\text { publicado/País }\end{array}$ & $\begin{array}{l}\text { Sujeitos } \\
\text { envolvidos }\end{array}$ \\
\hline 1 & LILACS & $\begin{array}{l}\text { Construção de cartilha educativa } \\
\text { sobre cuidados com crianças frente } \\
\text { à pandemia COVID-19: relato de } \\
\text { experiência. }\end{array}$ & $\begin{array}{l}\text { Relato de experiência } \\
\text { Nível V }\end{array}$ & SILVA RCR, et al. (2020). & $\begin{array}{l}\text { Universidade Federal de } \\
\text { Alagoas. }\end{array}$ & $\begin{array}{l}\text { Revista Baiana de } \\
\text { Enfermagem/ } \\
\text { Brasil. }\end{array}$ & $\begin{array}{l}\text { Acadêmicos de } \\
\text { enfermagem. }\end{array}$ \\
\hline 2 & LILACS & $\begin{array}{l}\text { Diagnostic tests and clinical } \\
\text { characteristics of COVID-19 in } \\
\text { children: an integrative review. }\end{array}$ & $\begin{array}{l}\text { Revisão integrativa } \\
\text { Nível V }\end{array}$ & $\begin{array}{l}\text { NUNES MDR, et al. } \\
(2020) \text {. }\end{array}$ & Artigo de revisão. & $\begin{array}{c}\text { Revista Texto Contexto } \\
\text { de Enfermagem/ } \\
\text { Brasil. }\end{array}$ & - \\
\hline 3 & LILACS & $\begin{array}{l}\text { Os conceitos de Florence } \\
\text { Nightingale em tempos de pandemia } \\
\text { da COVID-19 retratados em história } \\
\text { em quadrinhos: relato de } \\
\text { experiência. }\end{array}$ & $\begin{array}{l}\text { Relato de experiência } \\
\text { Nível V }\end{array}$ & $\begin{array}{l}\text { BARBOZA LEM, et al. } \\
(2020) .\end{array}$ & $\begin{array}{l}\text { Escola de Enfermagem da } \\
\text { Universidade Federal no Rio } \\
\text { de Janeiro. }\end{array}$ & $\begin{array}{c}\text { Escola Anna Nery } \\
\text { Revista de Enfermagem/ } \\
\text { Brasil. }\end{array}$ & $\begin{array}{l}\text { Acadêmicos e } \\
\text { docentes } \\
\text { (extensionistas } \\
\text { universitários). }\end{array}$ \\
\hline 4 & LILACS & $\begin{array}{l}\text { Recomendações para o cuidado à } \\
\text { criança frente ao novo coronavírus. }\end{array}$ & $\begin{array}{l}\text { Revisão integrativa } \\
\text { Nível V }\end{array}$ & $\begin{array}{l}\text { PACHECO ST, et al. } \\
(2020) .\end{array}$ & - & $\begin{array}{l}\text { Revista Cogitare de } \\
\text { Enfermagem/ } \\
\text { Brasil. }\end{array}$ & - \\
\hline 5 & MEDLINE & $\begin{array}{l}\text { COVID-19: Challenges and } \\
\text { opportunities for research nursing } \\
\text { and nursing research on paediatric } \\
\text { intensive care. }\end{array}$ & $\begin{array}{l}\text { Estudo teórico } \\
\text { Nível V }\end{array}$ & MENZIES J (2020) & $\begin{array}{c}\text { Paediatric Intensive Care, } \\
\text { Birmingham Women's and } \\
\text { Children's NHS Foundation } \\
\text { Trust, Birmingham, Reino } \\
\text { Unido. }\end{array}$ & $\begin{array}{l}\text { Nurs Crit Care/ Reino } \\
\text { Unido. }\end{array}$ & $\begin{array}{l}\text { Enfermeira } \\
\text { pesquisadora. }\end{array}$ \\
\hline 6 & MEDLINE & $\begin{array}{l}\text { Medidas de prevenção e controle de } \\
\text { infecção neonatal por COVID-19: } \\
\text { revisão de escopo. }\end{array}$ & $\begin{array}{l}\text { Revisão de escopo } \\
\text { Nível V }\end{array}$ & $\begin{array}{l}\text { FREITAS BHBM, et al. } \\
(2020) .\end{array}$ & 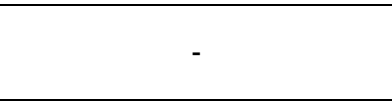 & $\begin{array}{l}\text { Revista Brasileira de } \\
\text { Enfermagem/ } \\
\text { Brasil. }\end{array}$ & - \\
\hline 7 & MEDLINE & $\begin{array}{l}\text { Safeguarding children with long-term } \\
\text { conditions from COVID-19. }\end{array}$ & $\begin{array}{l}\text { Estudo reflexivo } \\
\text { Nível V }\end{array}$ & GLASPER A (2020). & $\begin{array}{l}\text { Universidade de } \\
\text { Southampton/Reino Unido. }\end{array}$ & $\begin{array}{l}\text { British Journal of } \\
\text { Nursing/London. }\end{array}$ & Professor/autor. \\
\hline 8 & MEDLINE & $\begin{array}{l}\text { School Nurses on the Front Lines of } \\
\text { Healthcare: The Approach to } \\
\text { Maintaining Student Health and } \\
\text { Wellness During COVID-19 School } \\
\text { Closures. }\end{array}$ & $\begin{array}{l}\text { Estudo de caso } \\
\text { Nível IV }\end{array}$ & $\begin{array}{c}\text { ROTHSTEIN R, OLYMPIA } \\
\text { RP (2020). }\end{array}$ & Comunidade escolar. & $\begin{array}{l}\text { NASN Sch } \\
\text { Nurse/América do Norte. }\end{array}$ & $\begin{array}{c}\text { Escola/pais/comuni } \\
\text { dade/governo/profi } \\
\text { ssionais da saúde- } \\
\text { enfermagem. }\end{array}$ \\
\hline 9 & SCIELO & $\begin{array}{l}\text { A (in)visibilidade da criança em } \\
\text { vulnerabilidade social e o impacto do } \\
\text { novo coronavírus (COVID19). }\end{array}$ & $\begin{array}{l}\text { Estudo } \\
\text { Reflexivo } \\
\text { Nível V }\end{array}$ & $\begin{array}{l}\text { CHRISTOFFEL MM, et al. } \\
\text { (2020). }\end{array}$ & $\begin{array}{l}\text { Universidade Federal do Rio } \\
\text { de Janeiro. }\end{array}$ & $\begin{array}{l}\text { Revista Brasileira de } \\
\text { Enfermagem/ } \\
\text { Brasil. }\end{array}$ & $\begin{array}{c}\text { Crianças } \\
\text { brasileiras em } \\
\text { situação de } \\
\text { vulnerabilidade } \\
\text { social. } \\
\end{array}$ \\
\hline 10 & PUBMED & $\begin{array}{l}\text { COVID-19: Impact for Pediatric } \\
\text { Research, Evidence-Based Practice } \\
\text { and Quality Processes and Projects. }\end{array}$ & $\begin{array}{l}\text { Estudo } \\
\text { Reflexivo } \\
\text { Nível V }\end{array}$ & $\begin{array}{l}\text { GRALTON KS, et al. } \\
\text { (2020). }\end{array}$ & $\begin{array}{c}\text { Estados Unidos - Hospitais } \\
\text { pediátricos. }\end{array}$ & $\begin{array}{l}\text { J Pediatr Nurs. (Jornal } \\
\text { de enfermagem } \\
\text { pediátrica)/ Estados } \\
\text { Unidos. } \\
\end{array}$ & $\begin{array}{l}\text { Departamento de } \\
\text { Pesquisa em } \\
\text { Enfermagem. }\end{array}$ \\
\hline 11 & BEDENF & $\begin{array}{l}\text { Best practices in newborn care in } \\
\text { covid-19 times: an integrative review. }\end{array}$ & $\begin{array}{l}\text { Revisão integrativa } \\
\text { Nível V }\end{array}$ & GÓES FGB, et al. (2020). & - & $\begin{array}{l}\text { Revista Texto Contexto } \\
\text { de Enfermagem/ } \\
\text { Brasil. }\end{array}$ & - \\
\hline
\end{tabular}

Legenda: - sem informações. Fonte: Minasi ASA, et al., 2021. 


\section{DISCUSSÃO}

A análise dos dados possibilitou considerar alguns aspectos importantes quanto à atuação da enfermagem no cuidado à criança frente à COVID-19 que foram organizados em cinco categorias: realizar pesquisas na área para buscar conhecimentos e manter-se atualizado acerca da temática; cuidar de crianças com comorbidades; preparo e realização de exames diagnósticos da COVID-19; atuar como membro da equipe multiprofissional de saúde e atuar durante a internação hospitalar da criança.

\section{Realizar pesquisas na área na busca de conhecimentos e atualização}

É importante o enfermeiro instrumentalizar-se por meio da pesquisa para se apropriar de conhecimentos e manter-se atualizada para a realização do cuidado à criança infectada pelo coronavírus, minimizando seu impacto. Autores destacaram a pesquisa como um instrumento necessário. Apontaram o conhecimento como forma de fornecer subsídios para a realização do cuidado, associado a atualização deste tema, ainda, relativamente novo e cercado de dúvidas e descobertas (FREITAS BHBM, et al., 2020; GRALTON KS, et al., 2020; GÓES FGB, et al., 2020a; MENZIES J, 2020; PACHECO ST, et al., 2020; ROTHSTEIN R e OLYMPIA RP, 2020; BARBOZA LEM, et al., 2020; SILVA RCR, et al., 2020).

A literatura científica reforça a necessidade de conhecimento/informação sobre a COVID-19, atrelados à realização de treinamento, capacitação e criação de programas de educação continuada que contenham essa temática. A busca de conhecimentos, diante desta pandemia, apresenta-se como um desafio a ser vencido pelos profissionais de enfermagem, haja vista, os níveis elevados de transmissibilidade e mortalidade (GÓES FGB, et al., 2020b).

A enfermagem, além de adquirir conhecimento/informação pertinentes a infecção pelo coronavírus e também sobre a doença COVID-19, ainda, precisa estar preparada para repassá-las, de forma compreensível, à população. Tal comportamento assertivo, que contemple atualização constante destes profissionais, deve estar intrínseco no desempenho da profissão, pois reforçaria seu papel diante da saúde da população (PARREIRA ST, et al., 2020).

A literatura demonstra a necessidade de abertura de editais que fomentem à pesquisa para que sejam construídas estratégias de mitigação do Sar-Cov-2 e da COVID-19, possibilitando que a prática seja realizada baseada em evidencias. É preciso o envolvimento de Universidades, docentes e discentes de enfermagem em atividades tecnocientíficas tais como: projetos, pesquisas, produção de tecnologias, comitês de gestão, entre outras. Possibilitando, também, ampliar o conhecimento baseado em cientificidade, capacitando-os enquanto profissionais e, ainda, permitindo o compartilhamento da informação e experiências que possibilitem novas perspectivas de proteção e saúde frente ao novo coronavírus (COSTA R, et al., 2020).

\section{Cuidado às crianças com comorbidades}

Crianças com comorbidades apresentam-se como sendo as mais vulneráveis a infecção pelo Sar-Cov-2. Esse advento, pode estar relacionado as características das doenças subjacentes e seus respectivos tratamentos. Existem diversas condições crônicas e necessidades especiais de saúde que tornam a criança vulnerável à infecção pelo coronavírus. Além disso, muitas tiveram seus tratamentos comprometidos ou interrompidos pelo isolamento social (PACHECO ST, et al., 2020; GLASPER A, 2020).

A literatura aponta a maior suscetibilidade de crianças com comorbidades a desenvolver condições graves da COVID-19. Dentre elas, crianças portadoras de doenças cardiovasculares, renais e pulmonares crônicas, distúrbios imunológicos, câncer, anemia falciforme, diabetes, obesidade, entre outras (OUALHA M, et al., 2020). Estudo destacou a importância de atentarmos, também, para a obesidade infantil, pois está atrelada a alterações nutricionais, cardíacas, renais e imunológicas. Ela é um fator de risco, pois pode potencializar as complicações da COVID-19 em crianças, contribuindo para a necessidade de assistência ventilatória, risco de tromboembolismo, taxa de filtração glomerular reduzida, alterações na resposta imune inata e adaptativa e perpetuação da resposta inflamatória crônica (NOGUEIRA-DE-ALMEIDA CA, et al., 2020).

Algumas comorbidades fomentam um olhar mais atento da enfermagem no exercício do cuidado, pois as crianças que as possuem podem apresentar alterações durante a avaliação interferindo, inclusive, no diagnóstico da COVID-19, ou até predispondo a estarem propensas a um pior prognóstico. Por exemplo 
crianças cardiopatas, obesas, debilitadas podem apresentar alterações quando aferirmos a pressão arterial e ausculta cardíaca. Já aquelas mais acamadas, ou com alterações nutricionais podem apresentar risco de lesões por pressão, ou ainda, por estarem com sistema imunológico debilitado por questões nutricionais, ou provenientes do tratamento podem estar mais suscetíveis a risco de contaminação (EWENS B, et al., 2020).

Estudo de revisão sistemática da literatura do tipo Scoping Reviews também indicou, que em se tratando de crianças com comorbidades é recomendável promover a qualidade no cuidado e evitar a transmissibilidade do vírus Sar-Cov-2. Para isso é recomendado o distanciamento social; medidas de etiqueta respiratória; evitar circular em serviços de saúde sem urgência clínica; adotar protocolos operacionais de medidas de precaução rigorosas nos serviços de saúde; realizar o controle de sinais e sintomas das crianças, dos profissionais e cuidadores; realizar testagens virais e, ainda, utilizar a ferramenta de telemedicina como apoio ao acompanhamento da saúde dessas crianças (ANTUNES BS, et al., 2020).

\section{Preparo e realização de exames diagnósticos da COVID-19}

A enfermagem deve atuar e estar presente nas diferentes etapas do cuidado, desde a prevenção, diagnóstico e tratamento. Desta forma, o profissional enfermeiro deve priorizar o restabelecimento da criança, promovendo um cuidado centrado em suas necessidades. Deve atentar para eventuais alterações de sinais e sintomas, fazer o preparo adequado para a realização de exames que possam contribuir para a detecção, tratamento e reestabelecimento do quadro clínico da criança, auxiliando o restabelecimento apropriado e eficaz de sua saúde (NUNES MDR, et al., 2020).

Segundo estudo clínico, o diagnóstico da COVID-19 pode ser realizado pela reação em cadeia da polimerase (RT-PCR) com detecção dos ácidos nucléicos da SARS-CoV2, pelo sequenciamento do gene viral e pesquisa de anticorpos $\operatorname{lgM} / \mathrm{lgA}$ e $\mathrm{lgG}$. Os meios de coleta de material para a realização do diagnóstico podem ser através: swab faríngeo, swab nasofaríngeo (mais adequado para crianças), sendo que o escarro, fezes ou amostras de sangue, também, podem ser usados (CHU DKW, et al., 2020). Em estudo realizado na Espanha que avaliou as recomendações de manejo clínico pediátrico da infecção por Sar-Cov-2, a realização de exames de radiografia de tórax, tomografia, exames de sangue (hemograma, PCR, PCT, hemocultura, bioquímica com transaminases, íons, coagulação e gasometria) são indicados (CALVO C, et al., 2020).

Frente a necessidade de realização de exames recomenda-se a desinfecção de materiais após o uso e manutenção de distanciamento entre os pacientes. Sobretudo de pacientes em ventilação não invasiva, em casos necessários, pelo risco aumentado de contaminação por geração de aerossol (CALVO C, et al., 2020). A literatura científica aponta que os exames laboratoriais e radiológicos são ferramentas valiosas para 0 diagnóstico seguro da COVID-19. A enfermagem, além de atuar na coleta e preparo para a realização desses exames, possui capacidade de fazê-los, interpretá-los e articulá-los com o quadro clínico do paciente pediátrico, propiciando um diagnóstico seguro (ALMEIDA VRSRV, et al., 2021).

Desta forma, a enfermagem, nesse cenário pandêmico, é de extrema valia pelo papel que desempenha, pois possui olhar holístico e presta cuidados diretos ao paciente pediátrico. Atuando, desde o preparo, coleta e interpretação de exames e diagnósticos, e ainda, capaz de associar a sintomatologia e a evolução do quadro destes pacientes, atuando de maneira rápida e eficaz na recuperação e na prevenção de complicações oriundas da COVID-19 (ALMEIDA VRSRV, et al., 2021).

\section{Atuar como membro da equipe multiprofissional de saúde}

A prestação de serviços a saúde realizado de forma participativa entre os profissionais de saúde, mostrase mais eficaz e resolutiva quando envolve atendimento ao paciente. Todos os esforços dos enfermeiros devem estar voltados na busca da troca de conhecimentos e da realização de ações alinhadas com os outros profissionais e setores da área da saúde, propiciando o trabalho em equipes. Essas devem estar preparadas e instrumentalizadas para o cuidado e a atenção integral pertinentes ao vírus Sar-Cov-2 e a doença COVID19, sobretudo aquelas envolvendo as crianças. Esse esforço conjunto permite a troca de conhecimentos e potencializa a oferta de um cuidado mais eficaz e resolutivo com vistas à atenção integral ao paciente (CHRISTOFFE MM, et al., 2020).

Em revisão sistemática da literatura que objetivou avaliar a efetividade da estratégia de combinação de tarefas dos profissionais de saúde e do enfermeiro na Atenção Primária de Saúde (APS), constatou-se que 
quando o enfermeiro combina suas tarefas com as de outros profissionais expande e transcende suas funções habituais. Desta forma pode ocorrer maior valorização e visibilidade de sua atuação, assim como melhorar a provisão do cuidado, tornando-o mais eficaz. O trabalho em equipe multiprofissional contribui para a adesão do paciente, o que possibilita resultados positivos na melhoria da atenção em saúde da população e satisfação dos profissionais e clientes (CASSIANI SHB, et al., 2020).

Estudo destacou que neste ano, ainda pandêmico, demonstrou-se a importância desta classe no desempenho do trabalho em equipe e nas relações multidisciplinares com ênfase em processos de comunicação fluídos, com mensagens claras, concisas e transparentes. Comportamento que deve ser mantido no espaço da saúde e, sobretudo, nos cuidados da enfermagem (PARREIRA ST, et al., 2020).

\section{Atuação durante a internação hospitalar da criança}

A internação hospitalar de uma criança, envolvendo o Sar-Cov-2, apresenta-se como um momento em que o enfermeiro e sua equipe exercem um papel importante, pela proximidade com o paciente e seus familiares, sobretudo em relação ao cuidado, atentando, para que este possa ser exercido com qualidade e sem riscos. Em ambientes hospitalares, para que sejam realizados cuidados complexos, contínuos e as vezes prolongados, recursos envolvendo proteção (EPI) e tecnologias devem estar presentes na gestão e administração dos cuidados desempenhados pelos enfermeiros. Sua falta configura-se como um dos principais limites para a enfermagem prestar uma assistência livre de risco para si própria (CHRISTOFFEL MM, et al., 2020).

Apesar da literatura indicar baixa incidência e hospitalização de crianças diagnosticadas com a COVID19 , é oportuno que a enfermagem, que está presente desde o momento da admissão, tenha conhecimento clínico pertinentes a esta doença. Tais como: identificar sinais e sintomas mais comuns, alterações de exames laboratoriais e de imagem, que possibilite avaliar o paciente pediátrico de forma global. Isto irá favorecer a identificação rápida de eventuais complicações, através da sintomatologia e evolução do quadro clínico, promovendo a saúde de forma segura (ALMEIDA VRSRV, et al., 2021).

Cabe também considerar, ainda, aqueles pacientes pediátricos que necessitam de cuidados hospitalares e intensivos relacionados aos agravos decorrentes da COVID-19, em virtude de complicações envolvendo vias aéreas pulmonares, extrapulmonares e infecciosas. O enfermeiro e sua equipe devem dispor de preparo, clareza de distribuição de funções, dentro da equipe, para que estejam preparados e sejam disponibilizadas medidas como suporte ventilatório adequado, eficazes e céleres, considerando a necessidade de cada paciente, assim como seja possível, instauração de cuidados e técnicas avançadas quando necessárias (MORAES EM, et al., 2020).

Neste sentido, faz-se necessário, conforme destacou estudo realizado em Portugal, a capacidade da enfermagem em desempenhar gestão organizacional, neste momento pandêmico, sendo evidenciada nos ambientes hospitalares. Isto, propicia aspectos como articulação interdisciplinar, atenção ao controle de infecções, investimentos em capacitação, materiais e EPI e intervenções assertivas que propiciem o trabalho do enfermeiro, a fim de garantir o bem estar do paciente pediátrico e sua família durante o processo de internação hospitalar (PARREIRA ST, et al., 2020).

\section{CONSIDERAÇÕES FINAIS}

Evidenciou-se que a atuação do enfermeiro é multifacetada no cuidado à criança frente à Covid-19. Cabe a este profissional atuar ativamente na realização de medidas preventivas, ações de promoção à saúde da criança, detecção e cuidados de casos suspeitos e confirmados, minimizando a disseminação e as complicações que essas possam apresentar caso se infectem. Deve-se estabelecer estratégias de cuidados individualizado para cada criança infectada, considerando suas particularidades, comorbidades, fatores socioculturais, estrutura familiar, contribuindo para que ocorra a atenção integral e humanizada, favorecendo sua recuperação. Também, ficou evidenciado a necessidade de pesquisas e publicações pelos profissionais enfermeiros frente à esta temática, visto a dificuldade de encontrar nas bases de dados, nacionais e internacionais, artigos que demonstrem a atuação desses profissionais em relação aos cuidados à criança frente à Covid-19. 


\section{REFERÊNCIAS}

1. ALMEIDA VRSRV, et al. Características clínicas, laboratoriais e radiológicas da COVID-19 em crianças. Brazilian Journal of Development, 2021; 7(1): 9601-9615.

2. ANTUNES BS, et al. COVID-19 e crianças com doenças crônicas: revisão do escopo. Research, Society and Development, Vargem Grande Paulista, 2020; 9(12): 1-30. 2020.

3. BARBOZA LEM, et al. Os conceitos de Florence Nightingale em tempos de pandemia da COVID-19 retratados em história em quadrinhos: relato de experiência. Escola Anna Nery, 2020; 24 (Spe): 1-8.

4. CALVO C, et al. Recomendaciones sobre el manejo clínico de la infección por el «nuevo coronavirus» SARS-CoV2. Grupo de trabajo de la Asociación Espanola de Pediatría (AEP), 2020; 92(4): 241.

5. CASSIANI SHB, et al. Combinação de tarefas do enfermeiro e de outros profissionais na atenção primária em saúde: uma revisão sistemática. Revista Panamericana Salud Pública, 2020; 44.

6. CHRISTOFFEL MM, et al. A (in)visibilidade da criança em vulnerabilidade social e o impacto do novo coronavírus (COVID19). Revista Brasileira de Enfermagem, 2020; 73(Sup 2): 1-5.

7. CHU DKW, et al. Diagnóstico molecular de um novo coronavírus (2019-nCoV) causando um surto de pneumonia. Clinical Chemistry, 2020; 66(4): 549-555.

8. COSTA RLMM, et al. Ensino de enfermagem em tempos de covid -19: como se reinventar nesse contexto?. Texto contexto - enfermagem, 2020; 29: 1-3.

9. EWENS B, et al. What evidence informs the nursing care of people with class iii obesity in an acute care setting? A scoping review. Research Square, 2020; 1-11.

10. FREITAS BHBM, et al. Medidas de prevenção e controle de infecção neonatal por COVID-19: revisão de escopo. Revista Brasileira Enfermagem, 2020; 73 (Sup 2): 1-10.

11. GLASPER A. Safeguarding children with long-term conditions from COVID-19. British Journal of Nursing, 2020; 29(9), 533534.

12. GÓES FGB, et al. Best practices in newborn care in covid-19 times: an integrative review. Texto e Contexto - Enfermagem, 2020a; 29: 1-17.

13. GÓES FGB, et al. Desafios enfrentados pelos trabalhadores de enfermagem pediátrica diante da pandemia COVID-19. Revista Latino Americana Enfermagem, 2020b; 28: 1-9.

14. GRALTON KS, et al. COVID-19: Impact for Pediatric Research, Evidence-Based Practice and Quality Processes and Projects. Journal of Pediatric Nursing, 2020; 55: 264-265.

15. GU J, et al. COVID-19: Gastrointestinal Manifestations and Potential Fecal-Oral Transmission. Gastroenterology, 2020; 158(6): 1518-1519.

16. LASSANDRO G, et al. Children in Coronaviruses' Wonderland: What Clinicians Need to Know. Mediterranean Journal of Hematology and Infectious Diseases, 2020; 12(1): e2020042.

17. LEE B, RASZKA W. Covid-19 Tranmission and Children: The Child is Not to Blame. Pediatrics, 2020; e2020004879.

18. MENZIES J. COVID-19: Challenges and opportunities for research nursing and nursing research on pediatric intensive care. Nursing in Critical Care. 2020; 25(5): 321-323.

19. MINAYO MCS. O desafio do conhecimento: Pesquisa qualitativa em saúde. 9 ed. São Paulo: Hucitec; 2006.

20. NOGUEIRA-DE-ALMEIDA CA, et al. COVID 19 and obesity in childhood and adolescence: a clinical review. The Journal of Pediatrics, 2020; 96(5).

21. MORAES EM, et al. COVID-19: Nursing Care in an Intensive Care Unit. Scientia Medica, 2020; 30(1): e38468.

22. NUNES MDR, et al. Exames diagnósticos e manifestações clínicas da COVID-19 em crianças: revisão integrativa. Texto e Contexto - Enfermagem, 2020; 29: e20200156.

23. OUALHA M, et al. Severe and fatal forms of COVID 19 in children. Archives de Pédiatrie, 2020; 27(5): $235-238$.

24. ORGANIZAÇÃO PAN-AMERICANA DE SAÚDE (OPAS). OMS declara emergência de saúde pública de importância internacional por surto de novo coronavírus. Brasil, 2020. Disponível em: https: https://www.paho.org/bra/index.php? option=com_content\&view=article\&id=6100:oms-declara-emergencia-de-saude-publica-de-importancia-internacional-emrelacao-a-novo-coronavirus\&ltemid=812. Acesso em: 15 ago. 2020.

25. OXFORD CENTRE FOR EVIDENCE-BASED MEDICINE (OCFEM). Levels of evidence [Internet], 2009. Disponível: http://www.cebm.net/oxfordcentre-evidence-based-medicine-levels-evidencemarch-2009/. Acesso em: 10 set. 2020.

26. PACHECO ST, et al. Recomendações para o cuidado à criança frente ao novo coronavírus. Cogitare enfermagem, $2020 ; 25$.

27. PARREIRA ST, et al. Cuidados de Enfermagem em Tempos de Pandemia: Uma Realidade Hospitalar. Gazeta Médica, 2020; $7(2)$.

28. ROTHSTEIN R, OLYMPIA RP. School Nurses on the Front Lines of Healthcare: The Approach to Maintaining Student Health and Wellness During COVID-19 School Closures. National Association of School Nurses, 2020; 35(5): 269-275.

29. SILVA RCR, et al. Construção de cartilha educativa sobre cuidados com crianças frente a pandemia COVID-19: relato de experiência. Revista Baiana Enfermagem, 2020; 34: 1-7.

30. STRUYF T, et al. Sinais e sintomas para determinar se um paciente que se apresenta na atenção primária ou em ambientes ambulatoriais de hospital tem doença COVID-19. Cochrane database of systematic reviews, 2020; 7(7): 1-207.

31. TRILLA A. Un mundo, una salud: la epidemia por el nuevo coronavirus COVID. Medicina Clínica, 2020; $154(5): 175$.

32. VILELAS JMS. The new coronavirus and the risk to children's health. Revista Latino-Americana de Enfermagem, 2020; 28: e3320.

33. VIVANTI AJ, et al. Transmissão transplacentária da infecção por SARS-CoV-2. Nature Communications, $2020 ; 11: 3572$.

34. WHITTEMORE R, KNAFL K. The integrative review: updated methodology. Journal of advanced nursing, 2005; 52(5): 546553.

35. WIERENGA KL, MOORE SE. Adapting to Uncertainty: Nursing Responsiveness to COVID-19. Journal of Cardiovascular Nursing, 2020; 35(4): 322-323.

36. WORLD HEALTH ORGANIZATION (WHO). Director-General's openi'ng remarks at the media briefing on COVID-19-10 August 2020. 2020. Disponível em: https://www.who.int/dg/speeches/detail/who-director-general-s-opening-remarks-at-themedia-briefing-on-covid-19---10-august-2020. Acesso em: 06 abr. 2021.

37. WU C, et al. Single-cell RNA expression profiling of ACE2, the putative receptor of Wuhan 2019-nCoV, in the nasal tissue. MedRxiv, 2020. 